\title{
Anti-Inflammatory Polymeric Nanoparticles Based on Ketoprofen and Dexamethasone
}

\author{
Eva Espinosa-Cano ${ }^{1,2}$, Maria Rosa Aguilar ${ }^{1,2, *}$, , Yadileiny Portilla ${ }^{3}$, Domingo F. Barber ${ }^{3}(\mathbb{C}$ and \\ Julio San Román ${ }^{1,2}$ \\ 1 Biomaterials Group, Institute of Polymer Science and Technology (ICTP-CSIC), 28006 Madrid, Spain; \\ e.espinosa.cano@csic.es (E.E.-C.); jsroman@ictp.csic.es (J.S.R.) \\ 2 Networking Biomedical Research Centre in Bioengineering, Biomaterials and Nanomedicine (CIBER-BBN), \\ 28029 Madrid, Spain \\ 3 Department of Immunology and Oncology, and NanoBiomedicine Initiative, Spanish National Center for \\ Biotechnology (CNB-CSIC), 28049 Madrid, Spain; yportilla@cnb.csic.es (Y.P.); dfbarber@cnb.csic.es (D.F.B.) \\ * Correspondence: mraguilar@ictp.csic.es
}

Received: 10 June 2020; Accepted: 29 July 2020; Published: 31 July 2020

check for updates

\begin{abstract}
Polymeric nanoparticles that combine dexamethasone and naproxen reduce inflammation and synergistically inhibit Interleukin-12b (Il12b) transcription in macrophages. This effect can be the result of a cyclooxygenase-dependent or a cyclooxygenase-independent mechanism. The aim of this work is to obtain potent anti-inflammatory polymeric nanoparticles by the combination of dexamethasone and ketoprofen, one of the most efficient cyclooxygenase-inhibitors among non-steroidal anti-inflammatory drugs, with appropriate hydrodynamic properties to facilitate accumulation and co-release of drugs in inflamed tissue. Nanoparticles are spherical with hydrodynamic diameter $(117 \pm 1 \mathrm{~nm})$, polydispersity $(0.139 \pm 0.004)$, and surface charge $(+30 \pm 1 \mathrm{mV})$, which confer them with high stability and facilitate both macrophage uptake and internalization pathways to favor their retention at the inflamed areas and lysosomal degradation and drug release, respectively. In vitro biological studies concluded that the dexamethasone-loaded ketoprofen-bearing system is non-cytotoxic and efficiently reduces lipopolysaccharide-induced nitric oxide release. The RT-qPCR analysis shows that the ketoprofen nanoparticles were able to reduce to almost basal levels the expression of tested pro-inflammatory markers and increase the gene expression of anti-inflammatory cytokines under inflammatory conditions. However, the synergistic inhibition of $I l 12 b$ observed in nanoparticles that combine dexamethasone and naproxen was not observed in nanoparticles that combine dexamethasone and ketoprofen, suggesting that the synergistic trans-repression of $I l 12 b$ observed in the first case was not mediated by cyclooxygenase-dependent pathways.
\end{abstract}

Keywords: nanoparticles; ketoprofen; dexamethasone; inflammation; macrophages; M1 and M2 markers; Il12-p40 subunit

\section{Introduction}

Interleukin-12 (IL12) and interleukin-23 (IL23) have recently emerged as therapeutic targets in the treatment of autoimmune/inflammatory diseases and chronic inflammatory diseases in which the $T$ cell dominates as the primary dysfunctional cells [1-3]. IL12 and IL23 are mainly produced by antigen-presenting cells like macrophages and dendritic cells, and they play a key role in naïve T-cells differentiation to Th1 and Th17 cells, respectively [4]. Their combined inhibition has demonstrated potential in the treatment of a wide range of autoimmune/inflammatory diseases [5-8]. In 2000, it was discovered that IL12 and IL23 share the IL12-p40 subunit [9], and since then, its inhibition has become of therapeutic relevance. In fact, the FDA has recently approved Sterala (ustekinumab), a monoclonal 
antibody against this IL12-p40 subunit, for the treatment of Crohn's disease, psoriasis, psoriatic arthritis, and plaque psoriasis $[8,10]$. In a previous work, our group demonstrated that the nanoparticles (NPs) combining naproxen (NAP) and dexamethasone (Dx) have a synergistic effect on the repression of Il12b transcript levels, the gene that codifies for IL12-p40 in macrophages [11]. However, the mechanism for this synergistic inhibition was not elucidated. Currently, it is widely accepted that beneficial effects of non-steroidal anti-inflammatory drugs (NSAIDs) are mainly mediated by cyclooxygenase (COX)-dependent mechanisms but also via COX-independent pathways [12]. In fact, NSAIDs are known to exert anti-inflammatory effects through COX inhibition, ERK, JNK and p38 MAPK pathways, and 5-lipoxygenase (5-LO) pathways, among others [13]. There are reports of modulation of $I l 12 b$ expression in antigen-presenting cells (i.e., macrophages and dendritic cells, mainly) through all the aforementioned pathways [13-17]. NSAIDs as potent COX inhibitors, reduce the metabolism of arachidonic acid (AA) through the COX-dependent pathway reducing production of prostaglandins. However, accumulation of AA leads to increased metabolism through the 5-LO alternative pathway [18]. On the other hand, Dx inhibits phospholipase A2 (PLA2), the enzyme that mediates the production of AA from membrane phospholipids, reducing AA accumulation and both COX and 5-LO metabolic pathways [19]. Furthermore, regarding COX-independent mechanisms, Dx has been demonstrated to inhibit Il-12p40 expression in LPS-stimulated human monocytic cells by down-regulating the activation of JNK MAPK pathway [20]. According to that, NSAIDs/Dx synergistic suppression of Il12b expression could be the result of a COX-dependent or COX-independent mechanism. This work aims to prepare a new family of nanoparticle systems that combine physically entrapped Dx and covalently linked ketoprofen (KT), a well-known NSAID presenting several orders of magnitude lower $\mathrm{IC}_{50(\mathrm{COX})}$ than NAP [21,22], in order to obtain a system with a potent anti-inflammatory capacity and to elucidate if the COX-dependent mechanism plays a key role in the synergistic $I 112 b$ repression observed for the Dx/NAP system [11]. For this purpose, a methacrylic derivative of KT was prepared and copolymerized with 1-vinylimidazole (VI) by free radical polymerization obtaining a pseudo-gradient microstructure that enables self-assembly into NPs in aqueous media. The stability of the system and most suitable storage conditions were evaluated as a function of concentration, $\mathrm{pH}$, final volume, and freeze-drying. Hydrodynamic properties and surface charge of the NPs were optimized in order to favor macrophage uptake and the endocytic pathways for lysosomal targeting. Macrophage rapid uptake will favor the enhanced leaky vasculature and inflammatory cells sequestration (ELVIS) effect [11], and lysosome was considered the most appropriate organelle to favor enzymatic degradation and $\mathrm{pH}$-mediated co-delivery of the two drugs incorporated in the NPs [23]. Dx encapsulation efficiency was also evaluated by HPLC. Finally, biological activity of the system was studied by determining cytotoxicity, changes in the expression of LPS-induced inflammatory marker genes (i.e., Il12b, Il23a, and Tnfa), and anti-inflammatory marker genes (i.e., Vegfa, Tgfb1, and Il10) in RAW264.7 macrophages.

\section{Materials and Methods}

\subsection{Synthesis and Characterization of Ketoprofen-Derived Monomer (HKT)}

The methacrylic derivative of ketoprofen (HKT) (Figure 1a) was synthesized via esterification reaction as previously described for its homologous based on ibuprofen and naproxen [24,25]. Briefly, KT (TCI, 1 equiv) was dissolved in dichloromethane (DCM, Aldrich, St. Louis, MO, USA). Then, purified 2-hydroxyethyl methacrylate (HEMA, Aldrich, 1 equiv) and 4-dimethylaminopyridine (DMAP, Aldrich, 0.1 equiv) were added, and dicyclohexylcarbodiimide (DCC, 1 equiv. Fluka, Buchs, Switzerland) was slowly dropped into the reaction mixture under magnetic stirring and inert atmosphere $\left(\mathrm{N}_{2}(\mathrm{~g})\right)$. The reaction took place overnight, under continuous stirring, and at room temperature. The resultant mixture was filtered to eliminate $N, N^{\prime}$-diciclohexylurea (DCU) salt, and, subsequently, washed with water and a sodium bicarbonate-saturated solution $\left(\mathrm{NaHCO}_{3}\right.$, Panreac, Barcelona, Spain). Saturated $\mathrm{NaCl}$ (Panreac) and anhydrous magnesium sulphate $\left(\mathrm{MgSO}_{4}\right.$, Qemical, Esparraguera, Spain) were used to dry the final solution before DCM evaporation under reduced pressure. The structure and 
purity of the product were determined by proton nuclear magnetic resonance $\left({ }^{1} \mathrm{H}-\mathrm{NMR}\right)$ in a Varian Mercury $400 \mathrm{MHz}$ equipment using deuterated chloroform $\left(\mathrm{CDCl}_{3}\right.$, Aldrich) as a solvent at $25^{\circ} \mathrm{C}$.

a)
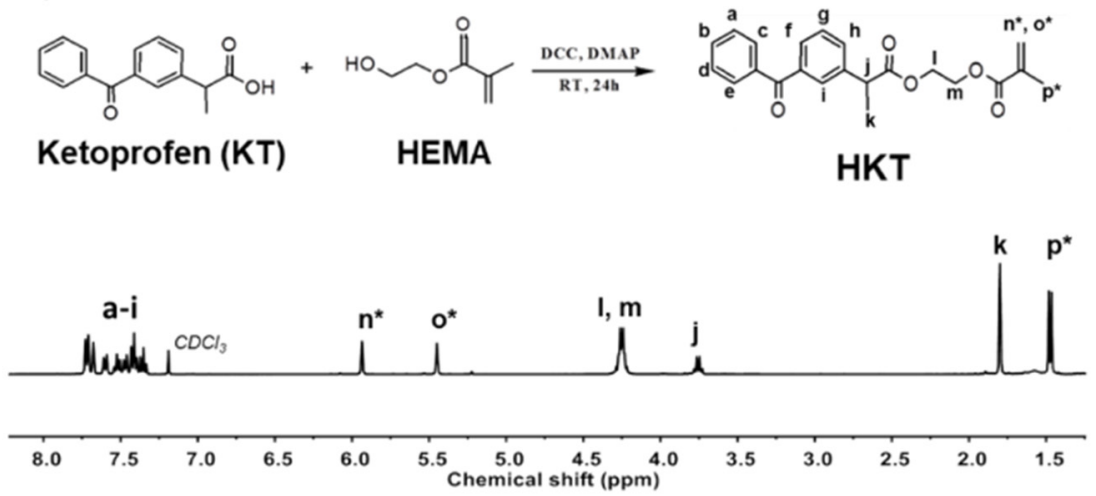

b)

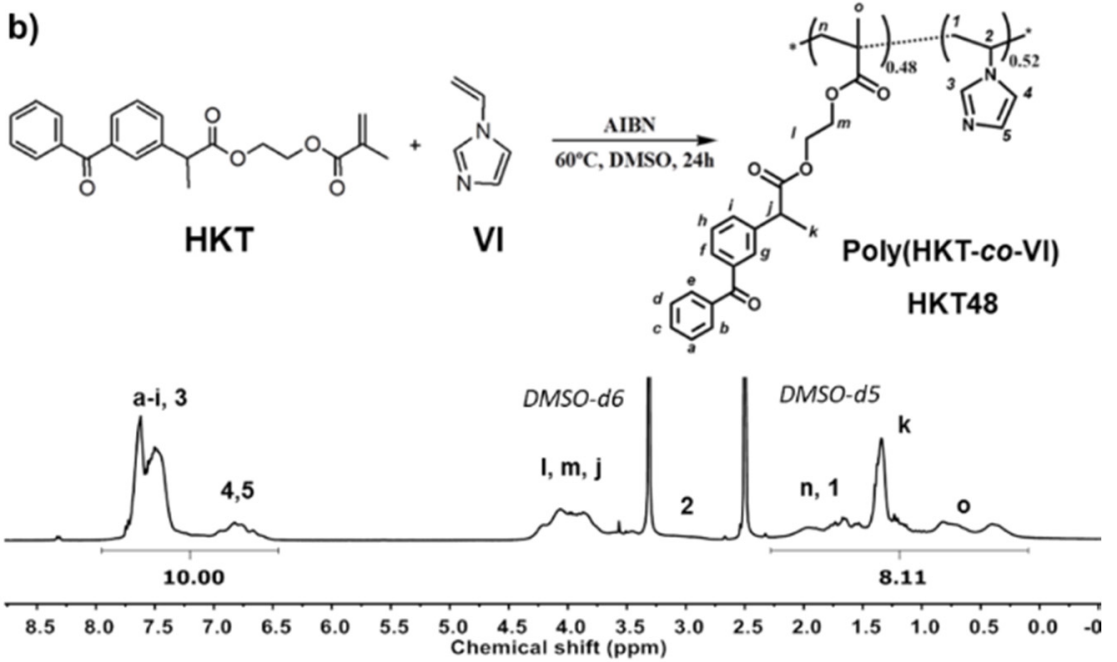

Figure 1. (a) Synthesis and ${ }^{1} \mathrm{H}-\mathrm{NMR}$ spectra of the methacrylic derivative of ketoprofen (HKT), and (b) synthesis via free radical copolymerization and ${ }^{1} \mathrm{H}-\mathrm{NMR}$ spectra of poly(HKT-co-VI) copolymer. Note: $\mathrm{n}$ * and $\mathrm{o}$ * refer to the cis and trans protons of the carbonyl group.

HKT: ${ }^{1} \mathrm{H}$ NMR $\left(400 \mathrm{MHz}, \mathrm{CDCl}_{3}\right) \delta_{H} 7.76-7.31(\mathrm{~m}, 9 \mathrm{H}), 5.96-5.91(\mathrm{~s}, 1 \mathrm{H}), 5.45(\mathrm{~s}, 1 \mathrm{H}), 4.35-4.17(\mathrm{~m}, 4 \mathrm{H})$, $3.76(q, J=7.2 \mathrm{~Hz}, 1 \mathrm{H}), 1.80(\mathrm{~s}, 3 \mathrm{H}), 1.47(d, 3 \mathrm{H})$.

\subsection{Synthesis and Characterization of Copolymer of Ketoprofen-Based Methacrylic Monomer and 1-vinyl imidazole, poly(HKT-co-VI)}

The copolymer based on HKT and 1-vinylimidazole (VI, Aldrich) was prepared via free radical polymerization (Figure $1 \mathrm{~b}$ ) and a feed molar content in HKT $\left(\mathrm{F}_{\mathrm{HKT}}\right)$ of 0.4 , and an initial monomers concentration ([M]) of $0.5 \mathrm{M}$ were used. In summary, HKT and VI were dissolved in dimethylsulfoxide (DMSO, Scharlau, Barcelona, Spain) at a concentration of $0.5 \mathrm{M}$, and after $10 \mathrm{~min}$ of deoxygenation with $\mathrm{N}_{2}$ (g), 2,2'-azobisisobutyronitrile (AIBN, $1.5 \times 10^{-2} \mathrm{M}$, Merck, Kenilworth, NJ, USA) was added. After $12 \mathrm{~h}$ at $60^{\circ} \mathrm{C}$, the copolymerization resultant mixture was dialyzed (Spectrum Laboratories, $3.5 \mathrm{~K}$ molecular weight cut-off) against distilled water for $72 \mathrm{~h}$, and the copolymer was isolated by freeze-drying as a white powder. Reactivity ratios of HKT and VI were studied by in situ ${ }^{1} \mathrm{H}-\mathrm{NMR}$ monitorization (see Supplementary Information for further details).

poly(HKT-co-VI)(48:52) (HKT48): ${ }^{1} \mathrm{H} N M R(400 \mathrm{MHz}, \mathrm{DMSO}-d 6) \delta_{H} 7.95-6.45(\mathrm{~m}, 12 \mathrm{H}(3 \mathrm{VI}+9 H K T))$, 4.53-3.39 ( $m, 5 H(5 H K T)), 3.22-2.73(s, 1 H(1 V I)), 2.28-0.10(m, 10 H(2 V I+8 H K T))$ 


\subsubsection{Proton Nuclear Magnetic Resonance $\left({ }^{1} \mathrm{H}-\mathrm{NMR}\right)$}

${ }^{1} \mathrm{H}-\mathrm{NMR}$ was performed in a Varian Mercury equipment operating at $400 \mathrm{MHz}$. Spectra were recorded by dissolving samples in deuteraded DMSO (DMSO-d6) at $25^{\circ} \mathrm{C}$. Copolymer composition was calculated using MestreNova 9.0 from the ${ }^{1} \mathrm{H}-\mathrm{NMR}$ integral between 7.92-6.47 ppm corresponding to the aromatic protons of both monomers and the integral between $2.28-0 \mathrm{ppm}$, which corresponds to protons of the methyl groups $\mathrm{k}$ and $\mathrm{o}$ of HKT and protons 1 and $\mathrm{n}$ from the main hydrophobic carbon chain of VI and HKT, respectively (Figure 1b).

\subsubsection{Size Exclusion Chromatography (SEC)}

HKT-based copolymer apparent average molecular weight $\left(\mathrm{M}_{\mathrm{n}}\right.$ and $\left.\mathrm{M}_{\mathrm{W}}\right)$ and polydispersity index (Đ) were determined by SEC, using a Perkin-Elmer Isocratic LC pump 250 coupled to a refraction index detector (Series 200). Two Resipore columns ( $250 \mathrm{~mm} \times 4.6 \mathrm{~mm}$, Varian, Palo Alto, CA, USA) were used as solid phase, degassed chromatographic-grade dimethylformamide (DMF, $0.7 \mathrm{~mL} / \mathrm{min}$, Scharlau, Barcelona, Spain) with $\operatorname{LiBr}(0.1 \% w / v)$ was used as eluent, and temperature was fixed at $70{ }^{\circ} \mathrm{C}$. Monodisperse PMMA standards (Scharlau) with molecular weights between 10,300 and $1,400,000$ Da were used to obtain the calibration curve. Data were analyzed using the Perkin-Elmer LC solution program.

\subsubsection{Differential Scanning Calorimetry (DSC)}

Glass transition temperature $\left(\mathrm{T}_{\mathrm{g}}\right)$ was determined by differential Scanning Calorimetry (DSC) with a Perkin Elmer DSC8500 interfaced to a Pyris thermal analysis data system. Dried samples (3-5 mg) were placed in aluminium pans and heated from -20 to $120^{\circ} \mathrm{C}$ at a constant speed of $20^{\circ} \mathrm{C} / \mathrm{min}$. $\mathrm{T}_{\mathrm{g}}$ was taken as the midpoint of the heat capacity transition.

\subsection{Preparation and Characterization of Self-Assembled Nanoparticles}

\subsubsection{Nanoprecipitation Method}

Poly(HKT-co-VI)-based NPs were prepared via nanoprecipitation method. Concisely, an organic solution (acetone (Scharlau): ethanol (Scharlau), 80:20 $(v / v))$; of the copolymer $(10 \mathrm{mg} / \mathrm{mL})$ was added dropwise to an aqueous buffer solution at $\mathrm{pH} 4(0.1 \mathrm{M}$ acetic acid and $0.1 \mathrm{M} \mathrm{NaCl})$, a pH below the reported $\mathrm{pK}_{\mathrm{b}}$ of VI (i.e., 5.5-6.1) [26]. The remaining organic solvent was eliminated by evaporation under continuous stirring overnight, and the resultant NPs were stored at $4{ }^{\circ} \mathrm{C}$.

\subsubsection{Characterization of NPs}

Hydrodynamic properties were optimized as a function of final volume $\left(\mathrm{V}_{\mathrm{F}}=10 \mathrm{~mL}, 20 \mathrm{~mL}\right.$ and $30 \mathrm{~mL}$ ) and final concentration ([NPs $]_{\mathrm{F}}=1 \mathrm{mg} / \mathrm{mL}$ and $5 \mathrm{mg} / \mathrm{mL}$ ), and the evolution of hydrodynamic properties of NPs was evaluated as a function of $\mathrm{pH}$ and time after freeze-drying and resuspension (Supporting Information). Particle size distribution and zeta potential $(\xi)$ were determined by dynamic light scattering (DLS) and laser Doppler electrophoresis (LDE), respectively, using a Malvern Nanosizer NanoZS Instrument equipped with a $4 \mathrm{~mW}$ He-Ne laser $(\lambda=633 \mathrm{~nm})$ at a scattering angle of $173^{\circ}$. Measurements were performed at $25^{\circ} \mathrm{C}$. For each sample, the statistical average and standard deviation of data were calculated from 3 measurements of 11 runs each, one in case of hydrodynamic diameter (Dh) and polydispersity (PdI) and 3 measurements of 20 runs each, one in case of $\xi$. SEM analysis of KT NPs was performed with a Hitachi SU8000 TED, cold-emission FE-SEM microscope working with an accelerating voltage $1 \mathrm{kV}$-D (see Supporting Information for more details).

\subsubsection{Dexamethasone and Coumarin-6 Encapsulation}

Dexamethasone (Dx, Aldrich, $\geq 98 \%$ pure; CAS Number: 50-02-2)-loaded NPs and coumarin-6 (c6)-loaded NPs were prepared by the described nanoprecipitation method with slight modifications. 
Dx $(5 \%, 10 \%, 15 \%$, or $20 \% w / w$ with respect to the polymer) or c6 (Aldrich, $1 \%$ w/w with respect to the polymer), and the corresponding polymer were dissolved in a mixture of acetone:ethanol (80:20, $v / v)$ and slowly dropped into the aqueous buffer solution (0.1 $\mathrm{M}$ Acetic Acid, $0.1 \mathrm{M} \mathrm{NaCl})$ at $\mathrm{pH} 4$ under magnetic stirring. NPs $(3 \mathrm{mg} / \mathrm{mL})$ were dialyzed against the same buffer for $72 \mathrm{~h}$ to eliminate remaining organic solvents and the soluble non-entrapped Dx or c6. The resultant NPs were filtered through $1 \mu \mathrm{m}$ Nylon filters (Whatman Puradisc) to eliminate insoluble Dx or c6

\subsubsection{Encapsulation Efficiency (\%EE) and Loading Capacity (\%LC)}

The powder resulting from freeze-drying of Dx-loaded NPs and c6-loaded NPs was dissolved in $2 \mathrm{~mL}$ of acetone:ethanol $(80: 20, v / v)$. This led to the disassembly of nanoparticle structure and release of the encapsulated drug. After organic solvent evaporation overnight, the copolymer-Dx mixture and the copolymer-c6 mixture were dissolved in acetonitrile:water (80:20,v/v) or ethanol, respectively, to precipitate the polymer. Centrifugation at 10,000 rpm for $5 \mathrm{~min}$ at RT separated the NPs pellet from the Dx and c6-containing supernatant, which were analyzed by HPLC (Dx, $\left.\lambda_{\mathrm{abs}}=239 \mathrm{~nm}\right)$ and UV spectrophotometry $(\mathrm{c} 6, \lambda \mathrm{abs}=459 \mathrm{~nm})$, correspondingly. Encapsulation efficiency $(\% \mathrm{EE}) \mathrm{was}$ computed using Equation (1) and the loading capacity (\%LC) using Equation (2). According to this, NPs were labeled as XY-KT NPs being X the encapsulation efficacy and Y the drug or dye encapsulated.

$$
\begin{aligned}
& \text { Encapsulation Efficiency }(\%)=\frac{[D x / c 6]_{\text {measured }}}{[D x / c 6]_{\text {initial }}} \times 100 \\
& \text { Loading capacity }(\%)=\frac{\text { mass of Dx/c6 measured }}{\text { mass of NPs }} \times 100
\end{aligned}
$$

\subsection{Cell Culture}

RAW264.7 murine macrophages (Sigma-Aldrich) were cultured in high-glucose Dulbecco's modified Eagle's medium (DMEM; Sigma, Saint Louis, MO, USA) supplemented with 10\% $(v / v)$ fetal bovine serum (FBS; Gibco, BRL), 2\% (v/v) L-Glutamine (Sigma, Saint Louis, MO, USA), and 1\% (v/v) Penicillin-G (Sigma, Saint Louis, $\mathrm{MO}, \mathrm{USA}$ ) at $37^{\circ} \mathrm{C}, 5 \% \mathrm{CO}_{2}$, and $90 \%$ relative humidity.

\subsubsection{Uptake Rate of c6-Loaded KT NPs by RAW264.7 Macrophages}

RAW264.7 cells were seeded into 6-well plates $\left(1.7 \times 10^{5}\right.$ cells $\left./ \mathrm{mL}\right)$ in complete DMEM. The cells were incubated overnight. The medium was replaced with the corresponding c6-loaded KT NPs suspension in DMEM (NPs:DMEM $(1: 5, v / v)$, Figures S1 and S2) that was added. Cells were incubated with NPs over different times $1,2,4,6,8$, and $24 \mathrm{~h}$ at $37^{\circ} \mathrm{C}$. At each time point, cells were washed with cold PBS, harvested, and counted to normalize fluorescence/cell. Then, they were centrifuged at 10,000 rpm, the supernatant was discarded, and cell's pellet was lysed with ethanol. At this point, ethanol compromised the nanoparticle structure releasing and dissolving internalized c6. After further centrifugation at 10,000 rpm, fluorescence of supernatant was measured (458/540 nm, excitation/emission) by a Multi-Detection Microplate Reader Synergy HT (BioTek Instruments; Winooski, VT, USA).

\subsubsection{Route of Nanoparticle Internalization}

RAW264.7 macrophages, cells were preincubated with chlorpromazine (CHL; $50 \mu \mathrm{M}$, Sigma-Aldrich) to inhibit clathrin-mediated endocytosis, nystatin (NYST; $10 \mu \mathrm{g} / \mathrm{mL}$, Sigma-Aldrich) to inhibit caveolae-mediated endocytosis, and amiloride (AMI; $100 \mu \mathrm{M}$, Sigma-Aldrich) to inhibit macropinocytosis. After $30 \mathrm{~min}$ at $37^{\circ} \mathrm{C}$, the inhibitor solutions were removed, and freshly prepared c6-loaded KT NPs in medium (NPs:DMEM $(1: 5, v / v))$ were added $(0.25 \mathrm{mg} / \mathrm{mL})$ and further incubated for another $8 \mathrm{~h}$. Subsequently, the cells were washed and lysed as previously described. The groups treated with c6-loaded NPs but without inhibitor at $4^{\circ} \mathrm{C}$ or at $37^{\circ}$, were used as negative and positive 
control, respectively. The percentage uptake after treatment with the inhibitors was normalized to the positive control uptake, which was expressed as 100\% (Equation (3)).

$$
\% \text { Uptake }=\frac{[c 6] \text { inhibitor }}{[c 6] \text { control }} x 100
$$

\subsubsection{In Vitro Cytotoxicity Assay of NPs}

In a 96-well plate under permissive conditions, $2 \times 10^{5}$ live cells $/ \mathrm{mL}(100 \mu \mathrm{L} /$ well $)$ were seeded. After $24 \mathrm{~h}$, cells were treated with different concentrations of NPs suspension $(0.250,0.125,0.090$, $0.045,0.023$, or $0.011 \mathrm{mg} / \mathrm{mL}$; NPs:DMEM $(1: 5, v / v))$, and after $24 \mathrm{~h}$, cell viability was determined by AlamarBlue (Invitrogen) assay. Absorbance at $570 \mathrm{~nm}$ was measured using a Multi-Detection Microplate Reader Synergy HT (BioTek Instruments, Winooski, VT, USA). The treatments were done in replicates $(n=8)$. Results were expressed as \% of cell viability with respect to the control (cells treated with medium).

\subsubsection{Nitric Oxide (NO) Assay}

RAW264.7 macrophages were seeded in a 96-well plate $\left(2 \times 10^{5}\right.$ live cells $/ \mathrm{mL}, 100 \mu \mathrm{L} /$ well $)$. After $24 \mathrm{~h}$, cells were treated with lipopolysaccharide (LPS; CAS Number: 297-473-0, Sigma-Aldrich; $5 \mu \mathrm{g} / \mathrm{mL}$ ) and with different $[\mathrm{NPs}]_{\mathrm{F}}$ of KT NPs, 14Dx-KT NPs, or free Dx. After $24 \mathrm{~h}$ and $48 \mathrm{~h}$ of treatment, NO released by macrophages was determined using Griess reagent modified kit (Sigma-Aldrich) according to the manufacturer instructions. The treatments were done in replicates $(n=8)$, and results were expressed as mean \pm standard deviation of the percentage of $\mathrm{NO}$ released with respect to the control (LPS-activated cells with no further treatment or inflammatory conditions untreated (IC,U)).

\subsubsection{RNA Extraction, Reverse Transcription, Real-Time Quantitative PCR (RT-qPCR)}

The transcript levels of $\mathrm{M}_{1}-\left(I l 12 b, I l 23 a\right.$, and Tnfa) and $\mathrm{M}_{2}-(\mathrm{Tg} f b 1, I l 10$, and Vegfa) related genes were determined by quantitative RT-PCR. RAW264.7 cells were incubated $24 \mathrm{~h}$ with culture medium (non-inflammatory conditions, NIC) or with LPS $(5 \mu \mathrm{g} / \mathrm{mL})$ to simulate inflammatory conditions (IC,U), and either non-treated or treated with unloaded KT-NPs $(0.045 \mathrm{mg} / \mathrm{mL}$; NPs:DMEM $(1: 5, v / v)), 14 \mathrm{Dx}-\mathrm{KT}$ NPs $(5.1 \mu \mathrm{M}$ Dx and $0.045 \mathrm{mg} / \mathrm{mL}$ NPs; NPs:DMEM $(1: 5, v / v))$, or free Dx $(5.1 \mu \mathrm{M})$. Media were collected after $24 \mathrm{~h}$ of treatment to eliminate non-internalized NPs or free Dx, and cells were further incubated in culture medium up to 7 days. Culture medium was refreshed every $48 \mathrm{~h}$. Total RNA was extracted from cells after 1 and 7 days of NPs addition. PureLink RNA Mini Kit (Applied Biosystems, Foster City, CA, USA) was used for this purpose following manufacturer's instructions [27]. RNA concentration was quantified by measuring absorbance at 260 and $280 \mathrm{~nm}$ in a NanoDrop 1000 spectrophotometer (Thermo Scientific) and $40 \mathrm{ng}$ RNA/sample were transformed into cDNA using a MultiScribe reverse transcription-based reaction kit (Applied Biosystems) in the presence of an RNAse inhibitor (N8080119, Applied Biosystems) in a MyCycler thermocycler (Bio-Rad; with the following temperature profile: $\left.25^{\circ} \mathrm{C}-10 \mathrm{~min}, 37^{\circ} \mathrm{C}-2 \mathrm{~h}, 85^{\circ} \mathrm{C}-5 \mathrm{~min}, 4^{\circ} \mathrm{C}-\infty\right)$. Table $\mathrm{S} 1$ shows the list of specific primers used for quantitative PCR (all from Sigma). The reaction was performed using the Power SYBR Green PCR Master Mix (Applied Biosystems), in an ABI PRISM 7900HT Real-Time PCR System (Applied Biosystems with the following temperature profile: $95{ }^{\circ} \mathrm{C}-15 \mathrm{~s}, 60{ }^{\circ} \mathrm{C}-60 \mathrm{~s}, 40$ cycles). Melting curves were generated in order to verify the specificity of the amplification ( $15 \mathrm{~s}$, from $60{ }^{\circ} \mathrm{C}$ to $95^{\circ} \mathrm{C}$ ). RT-qPCR expression data were analyzed according to the $2^{-\Delta \Delta C t}$ method (Livak et al., 2001) or as $2^{-\Delta C t}$ normalized to $\beta$-actin, and array views were generated using $\mathrm{MeV}$ software. 


\section{Results and Discussion}

\subsection{Methacrylic Derivative of Ketoprofen Monomer (HKT)}

A methacrylic derivative of ketoprofen was synthesized with yields above $90 \%$ and high purity as confirmed by ${ }^{1} \mathrm{H}-\mathrm{NMR}$ spectroscopy (Figure 1a). KT was linked through the carboxylic group, the main contributor to gastrointestinal adverse effects, to HEMA, forming an ester bond which is susceptible to hydrolysis under acidic conditions and/or by esterases. $\mathrm{pH}$ values between 5.5 and 6.0 and high esterase concentration are encountered in the lumen of lysosomes [28]. Altogether, this may provide a pH/enzyme-accelerated release of $\mathrm{KT}$ at inflamed areas where $\mathrm{pH}$ values are around 6.4 [29], or in the lumen of lysosomes after sequestration by inflammatory cells.

\subsection{Synthesis and Characterization of Copolymer of Ketoprofen-Based Methacrylic Monomer and 1-Vinyl Imidazole, Poly (HKT-co-VI)}

The disappearance of the ${ }^{1} \mathrm{H}-\mathrm{NMR}$ vinyl proton signals of $\mathrm{HKT}$ and $\mathrm{VI}\left(\mathrm{CH}_{2-\mathrm{VI}}\right.$ between 4.5 and 5.0 ppm and $\mathrm{CH}_{2-\mathrm{HKT}}$ between 5.0 and $6.0 \mathrm{ppm}$ ), the new ${ }^{1} \mathrm{H}-\mathrm{NMR}$ signals resultant from the methylene protons of the backbone chains $\left(\mathrm{CH}_{3-\mathrm{m}}, \mathrm{CH}_{2-1}\right.$, and $\mathrm{CH}_{2-n}$ between 0.1 and $\left.2.8 \mathrm{ppm}\right)$, and the broadening of the signals as a result of the macromolecular nature of the copolymer (Figure 1b) confirmed the successful co-polymerization, at established initial conditions $\left(\mathrm{F}_{\mathrm{HKT}}=0.4\right.$ and $\left.[\mathrm{M}]=0.5 \mathrm{M}\right)$, of hydrophobic HKT, and hydrophilic VI was carried out by free radical polymerization (yield = 84\%).

The copolymers molar composition was quantitatively determined from their corresponding ${ }^{1} \mathrm{H}-\mathrm{NMR}$ spectra by considering the signals between 0.1 and $2.8 \mathrm{ppm}$ assigned to eight protons of HKT $\left(\mathrm{CH}_{3-\mathrm{k}}, \mathrm{CH}_{3-\mathrm{o}}\right.$, and $\left.\mathrm{CH}_{2-\mathrm{n}}\right)$ and two protons of $\mathrm{VI}\left(\mathrm{CH}_{2-1}\right)$ and the signals between 6.5 and $8.0 \mathrm{ppm}$ resultant from nine aromatic protons of HKT $\left(\mathrm{CH}_{-\mathrm{a}-\mathrm{i}}\right)$ and three aromatic protons of VI $\left(\mathrm{CH}_{-3,4,5}\right)$. The differences among copolymer HKT molar content $\left(\mathrm{F}_{\mathrm{HKT}}\right)$ and feed HKT molar content $\left(\mathrm{f}_{\mathrm{HKT}}\right)$ are explained by the two orders of magnitude difference in the reactivity ratios of the monomers (Figure S3) and the fact that total conversion was not reached. The molecular weight $\left(\mathrm{M}_{\mathrm{w}}\right)$ of the copolymer was $99 \mathrm{KDa}$, with polydispersity index values of 2.3 that correspond to those obtained from a conventional radical polymerization reaction. The copolymer presented a unique glass transition temperature $\left(\mathrm{Tg}=54{ }^{\circ} \mathrm{C}\right)$ indicating that no-phase segregation was observed, although a pseudo-block copolymer structure was obtained according to reactivity ratios.

\subsection{Preparation and Characterization of Self-Assembled Nanoparticles}

The aforementioned pseudo-block microstructure and the hydrophobic-hydrophilic balance provided the copolymers with the necessary properties for self-assembling by nanoprecipitation. NPs presented a hydrophobic core mainly formed by covalently linked KT and a hydrophilic shell mainly formed by VI. Nanoprecipitation method was performed as previously described, and NPs were labeled as KT NPs. SEM micrograph of the NPs confirmed the successful NPs' formation presenting spherical shape, slight polydispersity in size, and diameter of about $100 \mathrm{~nm}$ (Figure S4). Regarding hydrodynamic properties, a positive $\xi$ value of $+30 \pm 1 \mathrm{mV}$ was obtained, confirming the presence of VI protonable amine groups on the surface of the NPs and, according to literature, an indication of good stability in suspension [30]. They presented $D_{h}$ of $117 \pm 1 \mathrm{~nm}$ with low PdI values $(0.139 \pm 0.004)$. The spherical morphology, positive surface charge and diameters between 100 and 200 nm made KT NPs suitable for accumulation at inflamed areas [31,32] as well as for an improved sequestration by inflammatory cells avoiding lymphatic drainage $[33,34]$. The diameter or surface charge of KT NPs did not significantly vary with the different final concentration on the aqueous phase or final volumes under study. Within the studied ranges, the key variable was the concentration of copolymer in the organic phase, which, when increased, led to NPs with $50 \mathrm{~nm}$ larger diameter (Table 1). Finally, in order to explore the most suitable conditions for NPs storage, a pH study, stability in suspension study, and freeze-drying study were performed. Figure $2 \mathrm{a}$ shows the size distribution and the $\xi$ values of the KT NPs at different $\mathrm{pH}$ values (i.e., 4.0, 4.5, 5.0, and 5.5). At pH 5.5, a broadening 
of the size distribution curve and an increase in the intensity of the peak in the microscale, which might correspond to agglomerated NPs, were observed. A decrease in surface charge was observed as $\mathrm{pH}$ increases due to deprotonation of amine groups of VI as the $\mathrm{pH}$ approaches to the $\mathrm{pK}_{\mathrm{b}}$ of VI $\left(\mathrm{pK}_{\mathrm{b}}=5.0-6.0\right)$. The reduction in the electrostatic repulsion between particles caused NPs aggregation. Therefore, the synthesis was carried out at $\mathrm{pH} 4(0.1 \mathrm{M}$ acetic acid) to ensure the protonation of $\mathrm{VI}$ and the good stability of the NPs over time. Figure $2 b$ shows that, under these conditions, there were no significant changes in the hydrodynamic properties of KT NPs at 0 days, 14 days, and 28 days when stored at $4{ }^{\circ} \mathrm{C}$. Furthermore, NPs recovered their initial hydrodynamic properties after freeze-drying and dispersion in the buffer solution at $\mathrm{pH} 4.0$ when sonicated for $10 \mathrm{~min}$ with an ultrasound tip $(30 \%$ amplitude) (Figure 2c). Therefore, NPs can be stored in powder or in suspension at $\mathrm{pH} 4.0$ and $4{ }^{\circ} \mathrm{C}$ for at least one month.

Table 1. Hydrodynamic properties (i.e., hydrodynamic diameter $\left(D_{h}\right)$, polydispersity of size distribution (PdI), and zeta potential ( ()$)$ of KT NPs at a different final concentration of nanoparticles in the aqueous phase $\left([\mathrm{NPs}]_{\text {A.P. }}\right)$ and at different final volumes $\left(\mathrm{V}_{\mathrm{F}}\right)$.

\begin{tabular}{|c|c|c|c|c|c|}
\hline$[\mathrm{NPs}]_{\text {A.P. }}{ }^{a}$ & $\mathrm{~V}_{\mathrm{F}}(\mathrm{mL})$ & [HKT48] $_{\text {O.P. }}{ }^{b}$ & $D_{h}{ }^{c}(n m)$ & PdI ${ }^{d}$ & $\xi^{e}(\mathrm{mV})$ \\
\hline \multirow{3}{*}{$1.0 \mathrm{mg} / \mathrm{mL}$} & 10 & $10 \mathrm{mg} / \mathrm{mL}$ & $117 \pm 1$ & $0.139 \pm 0.004$ & $+29 \pm 1$ \\
\hline & 20 & $10 \mathrm{mg} / \mathrm{mL}$ & $119 \pm 3$ & $0.153 \pm 0.018$ & $+29 \pm 1$ \\
\hline & 30 & $10 \mathrm{mg} / \mathrm{mL}$ & $116 \pm 1$ & $0.142 \pm 0.027$ & $+30 \pm 1$ \\
\hline \multirow{3}{*}{$5.0 \mathrm{mg} / \mathrm{mL}$} & 10 & $10 \mathrm{mg} / \mathrm{mL}$ & $115 \pm 1$ & $0.124 \pm 0.008$ & $+30 \pm 1$ \\
\hline & 20 & $10 \mathrm{mg} / \mathrm{mL}$ & $119 \pm 1$ & $0.112 \pm 0.013$ & $+31 \pm 1$ \\
\hline & 30 & $15 \mathrm{mg} / \mathrm{mL}$ & $163 \pm 3$ & $0.186 \pm 0.021$ & $+29 \pm 1$ \\
\hline
\end{tabular}

${ }^{a}$ Final concentration of nanoparticles (NPs) in the aqueous phase, ${ }^{b}$ concentration of copolymer in the organic phase, ${ }^{\mathrm{c}}$ mean hydrodynamic diameter. and ${ }^{\mathrm{d}}$ polydispersity of the size distribution obtained by dynamic light scattering (DLS), ${ }^{\mathrm{e}}$ mean zeta potential obtained by laser Doppler electrophoresis (LDE).
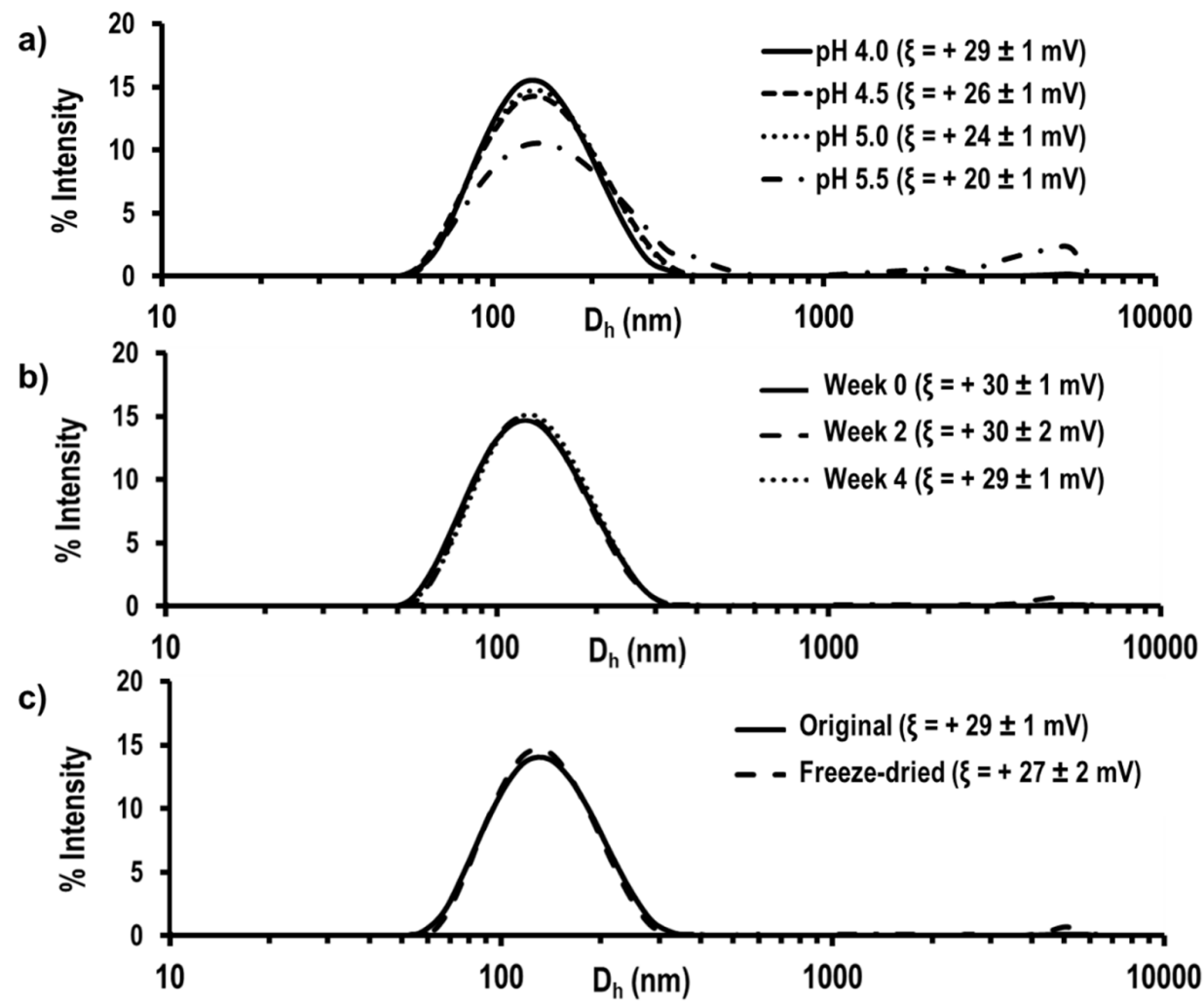

Figure 2. Size distribution (by intensity) and z-potential ( $\xi$ ) of ketoprofen (KT) NPs measured (a) at different $\mathrm{pH}$ values or at $\mathrm{pH} 4.0 ;(\mathbf{b})$ at day 0 and after 28 days stored at $4{ }^{\circ} \mathrm{C}$; and (c) before freeze-drying (dashed line) and after freeze-drying and tip sonication for $10 \mathrm{~min}$. 


\subsection{Dexamethasone and Coumarin-6 Encapsulation}

NPs were labeled as XY-KT NPs, with X being the encapsulation efficacy, and Y the drug or dye encapsulated. To achieve the maximum final concentration of Dx in our systems, we performed a screening of different $w / w$ percentages with respect to the copolymer $(5 \% w / w, 10 \% w / w, 15 \% w / w$, and $20 \% w / w)$, and the final mass of Dx encapsulated was computed by HPLC (Figure S5). The formulation with $15 \% w / w$ of Dx with respect to the copolymer was chosen for further experiments as it reached the highest Dx \%EE and \%LC (14\% and 3.85\%, respectively). The amount of drug encapsulated correlated with an increase in $D_{h}$ of the NPs $(140 \pm 1 \mathrm{~nm})$ and a reduction of the PdI value $(0.081 \pm 0.010)$. However, no significant differences were observed in $\xi$ values $(+29 \pm 1 \mathrm{mV})$. Interestingly, for a given concentration, the newly synthesized KT NPs encapsulated twice the amount of Dx than their NAP-bearing homologs [11], which might contribute to an improved anti-inflammatory effect. Coumarin-6 (c6) was used as a fluorescent probe in NPs internalization cellular studies. The dye was encapsulated at a low $\% w / w$ (i.e., $1 \% w / w$ ) to avoid fluorescence quenching. Table 2 summarizes the hydrodynamic properties and zeta potential of Dx-loaded, c6-loaded, and unloaded KT NPs.

Table 2. Summary of encapsulation efficiency (\%EE), loading capacity (\%LC), and hydrodynamic properties (i.e., mean hydrodynamic diameter $\left(\mathrm{D}_{\mathrm{h}}\right)$, polydispersity of size distribution $(\mathrm{PdI})$, and zeta



\begin{tabular}{cccccc}
\hline Sample & \% EE $^{\mathbf{a}}$ & ${\text { \% } \mathbf{~ L C ~}^{\mathbf{b}}}^{\mathbf{b}}$ & $\mathbf{D}_{\mathbf{h}^{\mathbf{c}}} \mathbf{( \mathbf { n m } )}$ & PdI $^{\mathbf{d}}$ & $\xi^{\mathbf{e}}(\mathbf{m V})$ \\
\hline KT NPs & - & - & $117 \pm 1$ & $0.139 \pm 0.004$ & $+30 \pm 1$ \\
14Dx-KT NPs & 14 & 3.85 & $140 \pm 1$ & $0.081 \pm 0.010$ & $+29 \pm 1$ \\
47c6-KT NPs & 47 & 0.47 & $126 \pm 2$ & $0.154 \pm 0.021$ & $+32 \pm 2$ \\
\hline
\end{tabular}

${ }^{a}$ Percentage of encapsulation efficiency of coumarin- $6,{ }^{b}$ percentage of loading capacity of coumarin- $6,{ }^{c}$ mean hydrodynamic diameter, and ${ }^{\mathrm{d}}$ polydispersity of the size distribution obtained by DLS, ${ }^{\mathrm{e}}$ mean zeta potential obtained by LDE.

\subsection{Uptake Rate of c6-Loaded NPs by RAW264.7 Macrophages}

A fast uptake of NPs by inflammatory cells is crucial for retention at inflamed areas [11], and the route by which they are internalized determines their fate inside the cell [35]. Fluorescent c6-loaded NPs were prepared as described before. They were used to monitor NPs internalization by RAW264.7 macrophages over $24 \mathrm{~h}$ of exposure at $37^{\circ} \mathrm{C}$ (Figure 3a). Figure 3 a shows the mass of c6 internalized per cell at different time points (i.e., 1, 2, 4, 6, 8, and $24 \mathrm{~h}$ ). The uptake rate of NPs was linearly increasing up to $24 \mathrm{~h}$ without reaching a plateau, an indication of rapid internalization. However, it was important to differentiate the possible surface adsorption of cationic nanoparticles on the negatively charged cell membrane from actual internalization. To do that, the uptake study was conducted at $4{ }^{\circ} \mathrm{C}$, relying on the decreased membrane recycling occurring at this temperature [36]. The cellular uptake was negligible when incubated at $4{ }^{\circ} \mathrm{C}$ in comparison to uptake at $37^{\circ} \mathrm{C}$ (Figure 3b), demonstrating the energy-dependent internalization of NPs. The endocytic pathways involved in the cellular uptake of the system were investigated, employing endocytic inhibitors of the main routes used by cationic nanomedicines to enter cells: chlorpromazine ( $\mathrm{CHL}$, clathrin-dependent endocytosis), amiloride (AMI, macropinocytosis), and nystatin (NYST, caveolae-mediated endocytosis) (Figure 3b) [35]. When treated with CHL, cellular uptake of KT NPs was reduced by $36 \pm 2 \%(p<0.05)$ with respect to the untreated positive control $\left(37^{\circ} \mathrm{C}\right)$, respectively. Additionally, pre-treatment AMI led to the reduction of internalization of NPs by $48 \pm 3 \%(p<0.05)$ relative to the positive control. However, no significant differences were observed after NYST pre-treatment. These results indicated that KT NPs internalization mainly occurred by clathrin-mediated endocytosis (CME) and macropinocytosis. These results correlate with reports of positively charged nanoparticles of $\sim 100 \mathrm{~nm}$ diameter predominantly internalized through CME mechanism [37] and those claiming that the electrostatic interactions with the negatively charged cell membrane facilitate cationic molecules internalization through macropinocytosis [23]. Internalization via CME and/or macropinocytosis is recognized to be a more destructive pathway 
compared to caveolae-mediated endocytosis [23,35]. Vesicle acidification and fusion with lysosomes occurring during CME and macropinocytosis might facilitate the release of both drugs due to the enhanced susceptibility of the ester bond to be degraded at acidic $\mathrm{pH}$ and in the presence of esterases. Therefore, the covalent ester bond that links KT to the polymeric backbone will be degraded, and the NPs self-assembled structure will be disrupted.

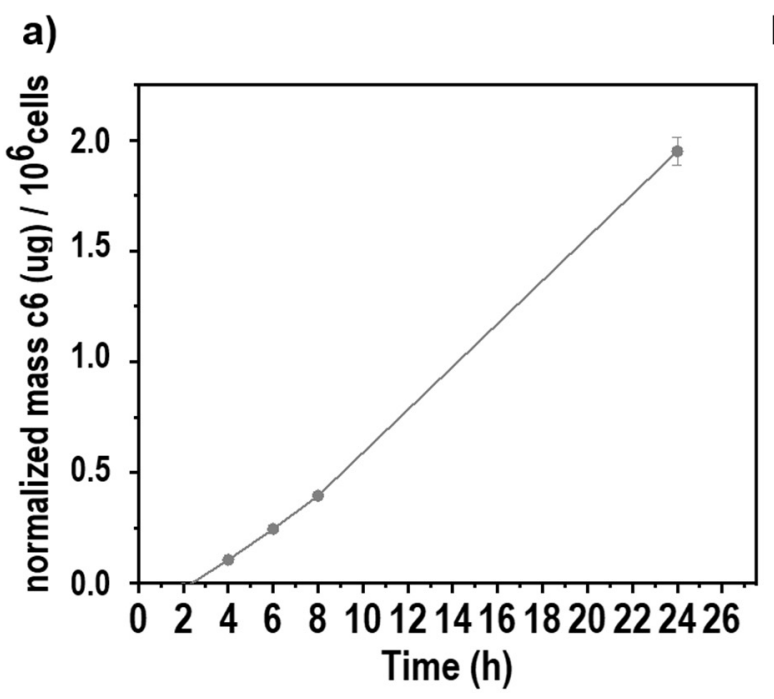

b)

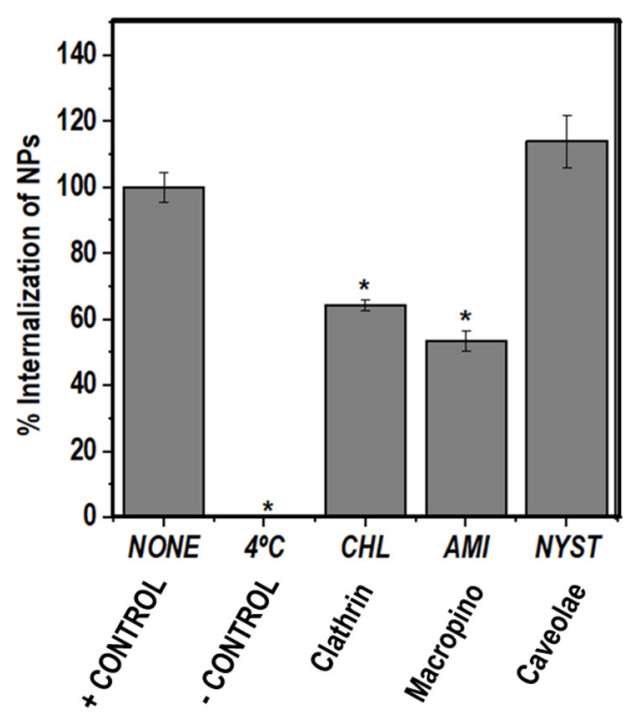

Figure 3. (a) Normalized mass of coumarin-6 (c6) internalized per cell at different time points for $47 \mathrm{c} 6-\mathrm{KT}$ NP, and (b) \%internalization of $47 \mathrm{c} 6-\mathrm{KT}$ NPs at $37^{\circ} \mathrm{C}$ (NONE, positive control), $4{ }^{\circ} \mathrm{C}$ (negative control), and at $37^{\circ} \mathrm{C}$ after pre-treatment with chlorpromazine (CHL), amiloride (AMI), and nystatin (NYST) $\left(*\right.$ : significant difference compared to NONE, $\left.{ }^{*} p<0.05\right)$.

\subsection{In Vitro Cytotoxicity Assay of NPs}

Cytotoxicity of free Dx (the concentration corresponds to the maximum concentration encapsulated in the NPs), 14Dx-KT NPs, and unloaded KT NPs was tested using murine macrophages (RAW264.7) as model inflammation-related cells. Figure 4 shows the cell viability compared to a control of untreated cells (i.e., non-inflammatory conditions, NIC). None of the concentrations tested were cytotoxic after $24 \mathrm{~h}$, as cell viability was always higher than $70 \%$, and for concentrations above $0.25 \mathrm{mg} / \mathrm{mL}$, it was never below $85 \%$ (ISO 10993-5:2009). There were no statistically significant differences ${ }^{*} p<0.05$ ) between Dx-loaded and unloaded NPs (i.e., 14Dx-KT NPs and KT NPs) or between free Dx and 14Dx-KT NPs at any of the tested concentrations. 


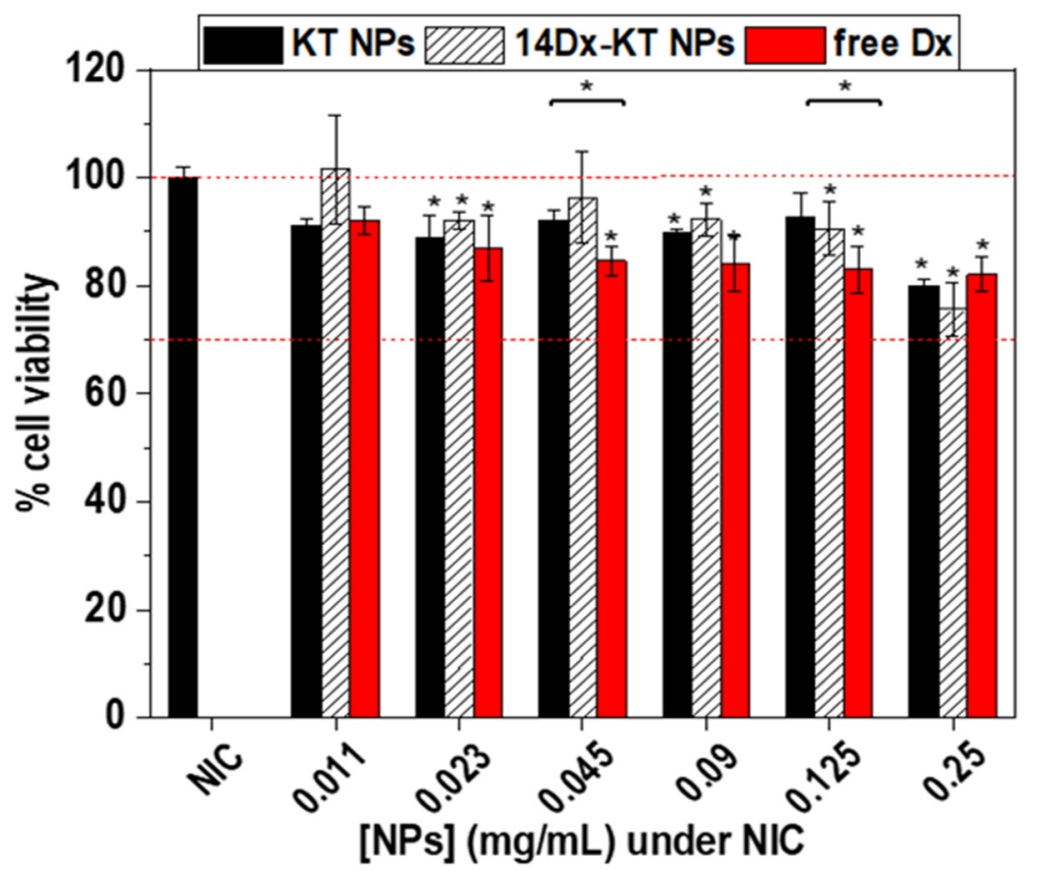

Figure 4. Cell viability of RAW264.7 macrophages treated with different concentrations of unloaded KT NPs (black), 14Dx-KT NPs (dashed white), or free Dx (red) over $24 \mathrm{~h}$. The diagrams include the mean, the standard deviation $(\mathrm{n}=8)$, and the ANOVA results $\left({ }^{*} p<0.05\right.$ statistically significant difference with cells under non-inflammatory conditions (NIC) and between the different systems).

\subsection{Effect of Polymeric Nanoparticles Based on Ketoprofen and Dexamethasone on Macrophage NO Levels}

Anti-inflammatory capacity of the systems after $24 \mathrm{~h}$ and $48 \mathrm{~h}$ was assessed by measuring the levels of nitric oxide (NO) released by lipopolysaccharide (LPS)-activated macrophages. When RAW264.7 cells are activated by LPS, they polarize to their pro-inflammatory phenotype $\left(\mathrm{M}_{1}\right)$ and they start overproducing NO, a well-known inflammatory mediator [38]. NO released was measured after $24 \mathrm{~h}$ (Figure 5a,b, black) and $48 \mathrm{~h}$ (Figure 5a,b, dashed white) of incubation with LPS and either KT NPs (Figure 5a) or 14Dx-KT NPs (Figure 5b) at different concentrations. KT NPs significantly (\# $p<10^{-5}$ ) improved reduced NO release after $48 \mathrm{~h}$ when compared to $24 \mathrm{~h}$, whereas NO levels were maintained overtime with 14Dx-KT NPs. This result indicated the faster anti-inflammatory effect of Dx-loaded NPs, which was physically entrapped, allowing an earlier release when compared to the covalently linked NSAID. Moreover, Figure 5c presents LPS-induced NO release after $48 \mathrm{~h}$ of LPS administration and challenging with different concentrations of unloaded KT NPs (black) 14Dx-KT NPs (dashed white) or free Dx (red). After $48 \mathrm{~h}$ of incubation, all systems counteracted LPS-induced NO release in a statistically significant manner for all concentrations tested $\left(\# p<10^{-5}\right)$ with respect to LPS treated cells (IC,U).

Results demonstrated that NO reduction capacity was maintained after $48 \mathrm{~h}$ at any of the concentrations tested in case of KT-based systems. Moreover, Dx-loaded systems performed better than free Dx at specific concentrations of KT-based systems ${ }^{*} p<0.05$; [NPs] $=0.045 \mathrm{mg} / \mathrm{mL}$ and $0.023 \mathrm{mg} / \mathrm{mL}$ ). One of these concentrations, $0.045 \mathrm{mg} / \mathrm{mL}$, was chosen for further RT-qPCR analysis as it was the maximum concentration of NPs with improved reduction of NO released levels and it will allow comparison with RT-qPCR results obtained for previously described NAP-based systems. Again, KT-based systems showed an improved behavior when compared to previously described NAP-based systems in terms of reduction of NO released levels at any of the two time points tested, especially Dx-loaded systems [11]. This might be attributed to the higher content in Dx (5.1 $\mu \mathrm{M}$ and $2.55 \mu \mathrm{M}$, respectively) and to the faster internalization of KT-based NPs. 
KT NPs

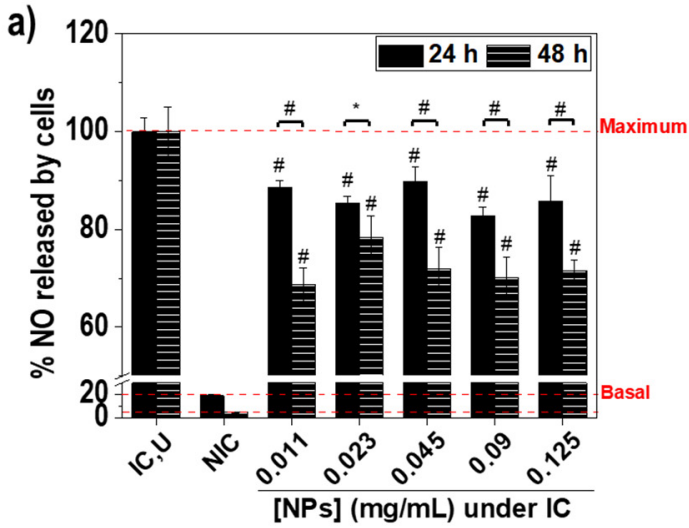

14Dx-KT NPs

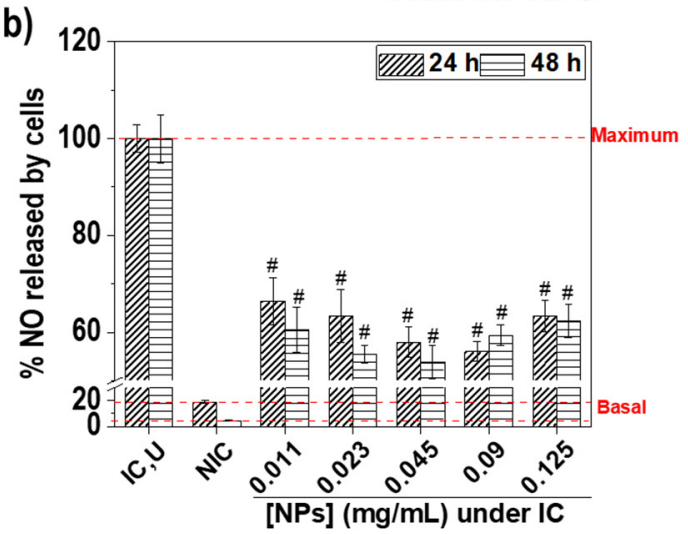

c)

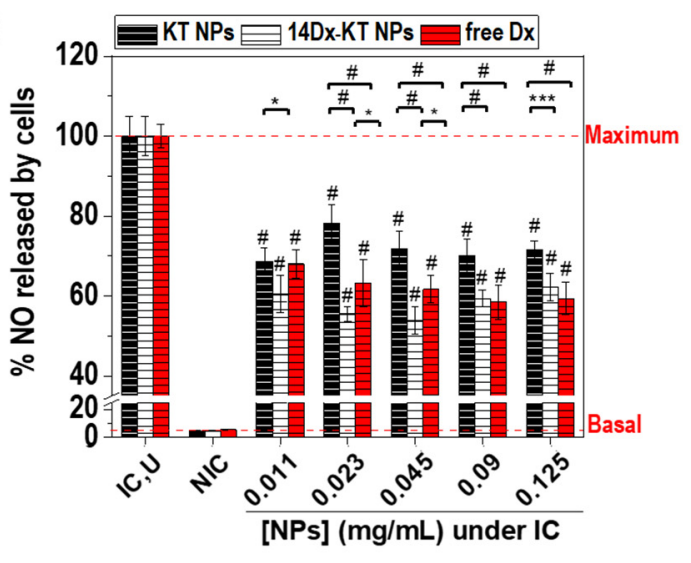

Figure 5. NO release by RAW264.7 macrophages after $24 \mathrm{~h}$ (black) and $48 \mathrm{~h}$ (dashed white) with no treatment (NIC), treatment with LPS alone (IC,U), and treatment with LPS and different concentrations of (a) unloaded KT NPs and (b) 14Dx-KT NPs; (c) NO release after $48 \mathrm{~h}$ with no treatment (NIC), treatment with LPS (IC,U), and treatment with LPS and different concentrations of loaded NAP NPs or KT NPs (black), 8Dx-NAP NPs or 14Dx-KT NPs (dashed white), or free Dx (red). The diagrams include the mean, the standard deviation ( $\mathrm{n}=8)$, and the ANOVA results $\left({ }^{*} p<0.05,{ }^{* * *} p<10^{-3}\right.$, and $\# p<10^{-5}$ statistically significant difference with IC, $\mathrm{U}$ cells or between $24 \mathrm{~h}$ and $48 \mathrm{~h}$ time points).

3.8. Real-Time PCR Analysis of the Expression of M1-M2 Specific Reference Genes after NPs Treatment in Non-Stimulated Macrophages and LPS-Stimulated Macrophages

A high positive surface charge of NPs has been reported as one of the external stimulus leading to $\mathrm{M}_{1}$ polarization of macrophages $[39,40]$. Because of this, the effect of cationic polymeric NPs based on ketoprofen and dexamethasone on $\mathrm{M}_{1}$-related gene transcript levels was studied in non-stimulated RAW264.7 cells (NIC) to analyze whether these NPs induce to some extent an $\mathrm{M}_{1}$ polarization. Figure 6 shows the transcript levels of Tnfa, Il12b, and Il23a determined by RT-qPCR after 1 day and 7 days of treatment with KT NPs $(0.045 \mathrm{mg} / \mathrm{mL})$ and 14Dx-KT NPs (5.1 $\mu \mathrm{M}$ Dx and $0.045 \mathrm{mg} / \mathrm{mL}$ NPs), and free Dx (5.1 mM). Results were expressed relative to the corresponding level of expression of each transcript in the untreated sample (i.e., non-inflammatory conditions, NIC). Figure S6 shows heat maps and Table S2 numerical RT-qPCR data. Figure 6 shows that there was no significant overexpression of $\mathrm{M}_{1}$ markers with respect to the control (NIC) after 1 day or 7 days of treatment with 14Dx-KT NPs; whereas after KT NPs treatment, only $I l 12 b$ was slightly overexpressed after 1 day of treatment. These data demonstrated that, although there was a slight activation of M1 marker genes, there were no significant long-term $\mathrm{M}_{1}$-polarization after treatment with cationic KT-based NPs. 


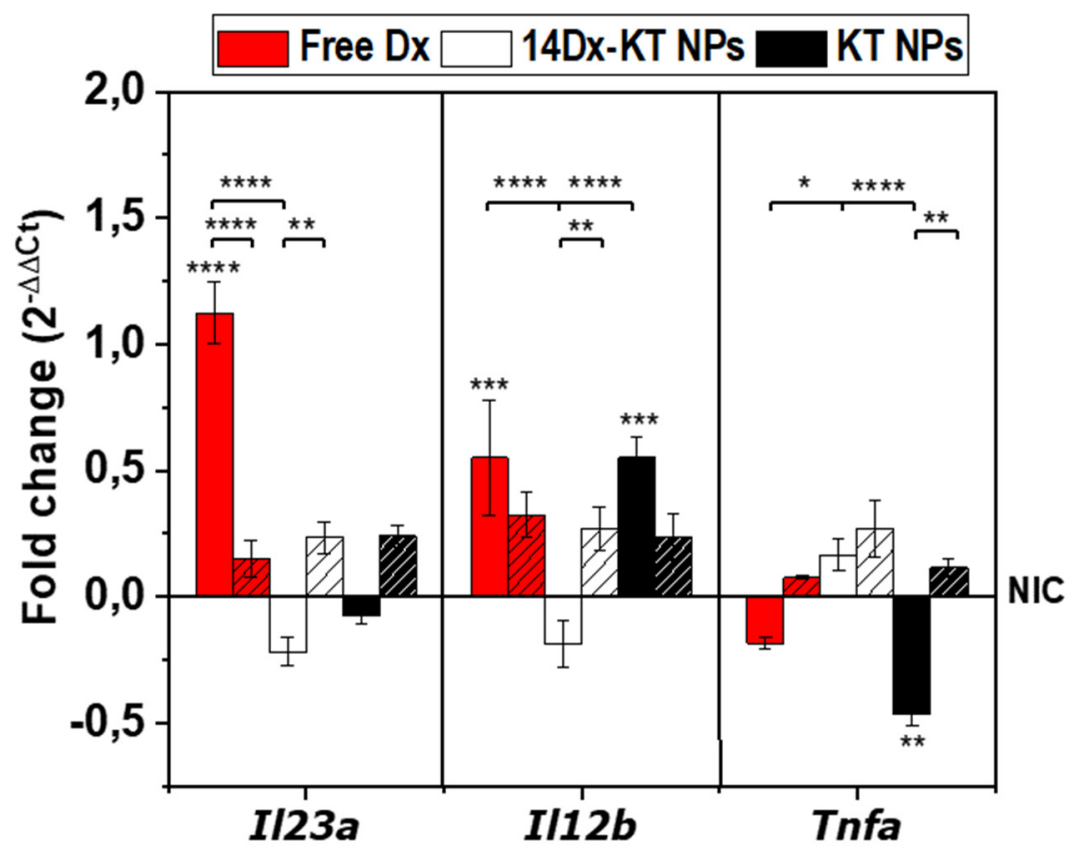

Figure 6. Quantitative real-time PCR data. Graphical presentation of gene transcript levels of $\mathrm{M}_{1}$ markers in non-LPS-activated samples (non-inflammatory condition, NIC) treated with free dexamethasone (free Dx, $5.1 \mu \mathrm{M}$, red), Dx-loaded ketoprofen-bearing NPs (14Dx-KT NPs, $5.1 \mu \mathrm{M}$ Dx, and $0.045 \mathrm{mg} / \mathrm{mL}$ NPs, white) and unloaded ketoprofen-bearing NPs (KT NPs, $0.045 \mathrm{mg} / \mathrm{mL}$, black) for 1 day (plain) and 7 days (dashed). Results are expressed relative to the corresponding level of expression of each transcript in the untreated sample. The diagrams include the mean, the standard deviation $(\mathrm{n}=2)$, and the ANOVA results $\left({ }^{*}\right.$ - comparison with untreated NIC control, ${ }^{*} p<0.05$, ** $p<0.01{ }^{* * *} p<0.001$ and $\left.{ }^{* * * *} p<0.0001\right)$.

Then, in a second set of experiments, the anti-inflammatory effect of the systems was analyzed under inflammatory conditions. RAW264.7 macrophages were cultured in the presence of LPS to mimic pro-inflammatory conditions and treated with either culture media (inflammatory conditions, untreated $(\mathrm{IC}, \mathrm{U}))$, free Dx $(5.1 \mu \mathrm{M})$, unloaded KT NPs $(0.045 \mathrm{mg} / \mathrm{mL})$ or $14 \mathrm{Dx}-\mathrm{KT}$ NPs $(5.1 \mu \mathrm{M}$ Dx and $0.045 \mathrm{mg} / \mathrm{mL}$ NPs). The expression of $\mathrm{M}_{1}$ and $\mathrm{M}_{2}$ (Figure 7) marker genes was presented relative to their corresponding levels in the untreated sample (NIC). Figure S7 shows heat maps and Table S2 numerical RT-qPCR data. Regarding $\mathrm{M}_{1}$ markers, when compared to basal cellular levels (NIC), LPS-treatment $(\mathrm{IC}, \mathrm{U})$ significantly increased transcript levels of Tnfa after 1 day of treatment and Il12b after 7 days of treatment, and it had no effect on Il23a. The short-term induction of Tnfa was reversed by all systems tested. However, after 7 days of treatment free of Dx and KT NPs did not affect the expression of Tnfa, while the system combining both (14Dx-KT NPs) induced a significant increase in expression of this gene. This might be occurring because of the PGE2 reduction after NSAID/GC combined treatment as both the GC and the NSAID contributed to reducing PGE2 levels [41]. Regarding Il12b expression, although 14Dx-KT NPs treatment caused the increase of $I l 12 b$ transcript levels after 1 day of treatment, all systems reversed the LPS-induced overexpression after 7 days of treatment, which was more significant in free Dx and Dx-loaded NPs. Moreover, 14Dx-KT NPs and KT NPs induced a slightly significant overexpression of $I l 23 a$ with respect to the LPS-treated control that was reversed after 7 days of treatment. Therefore, in the long term, Tnfa overexpression was accompanied by normal levels of III2b and Il23a. These findings correlate with the described dual role of Tnfa: as an initiator of inflammatory response early in the infection and selective regulator of inflammatory response in the later stages of inflammation [42]. 


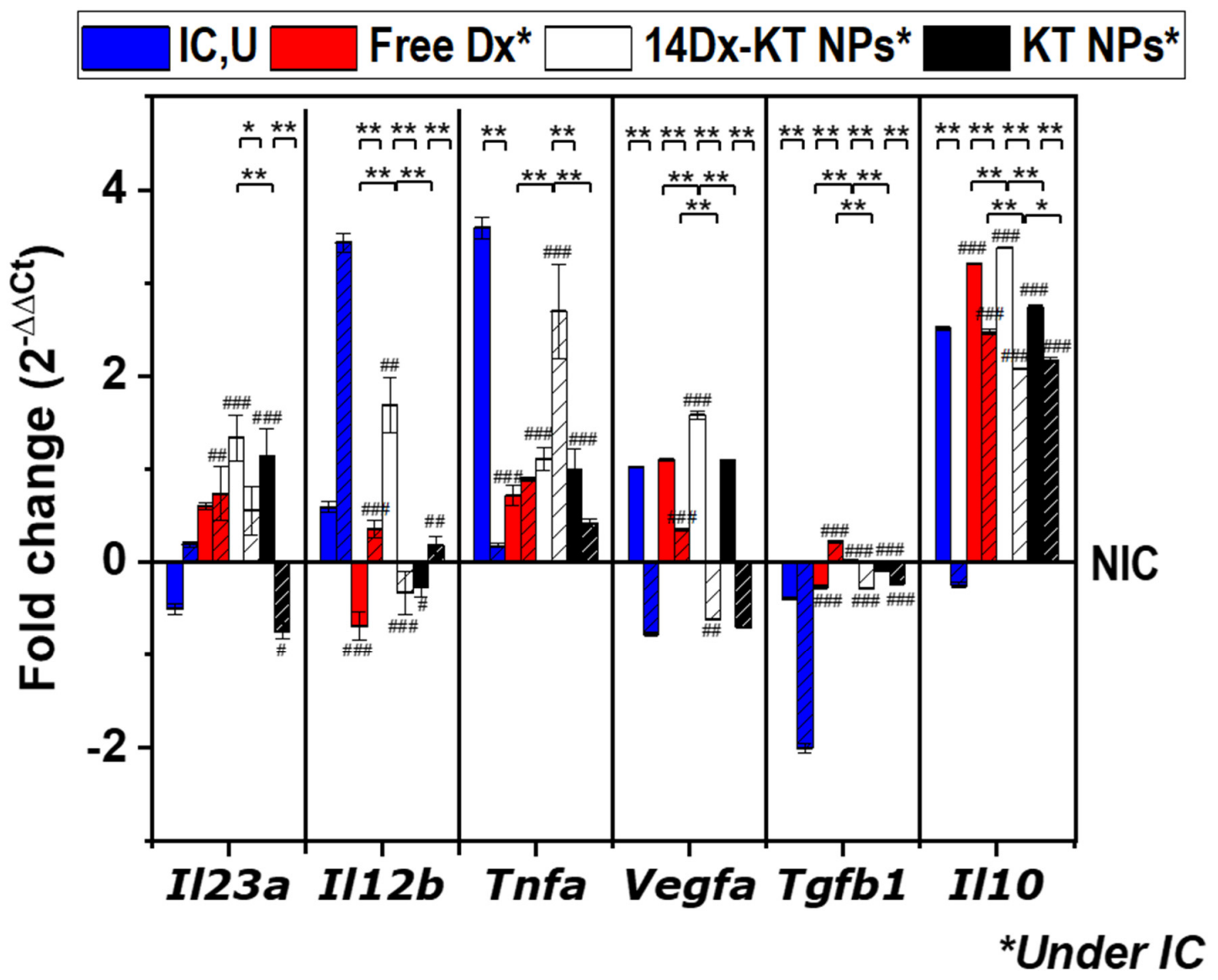

Figure 7. Quantitative real-time PCR data. Graphical presentation of gene transcript levels of $\mathrm{M}_{1}$ markers (Il23a, Il12b, and Tnfa) and of $\mathrm{M}_{2}$ markers (Vegfa, Tgfb1, and Il10) in samples treated with LPS (500 ng/mL) and either treated with culture media (IC,U, blue), free dexamethasone (free Dx, $5.1 \mu \mathrm{M}$, red), Dx-loaded ketoprofen-bearing NPs (14Dx-KT NPs, $5.1 \mu \mathrm{M}$ Dx and $0.045 \mathrm{mg} / \mathrm{mL}$ NPs, white), and unloaded ketoprofen-bearing NPs (KT NPs, $0.045 \mathrm{mg} / \mathrm{mL}$, black) for 1 day (plain) or 7 days (dashed). Results were expressed relative to the corresponding level of expression of each transcript in non-inflammatory conditions (RAW264.7 alone, NIC). The diagrams include the mean, the standard deviation ( $\mathrm{n}=2$ ), and the ANOVA results (\#-comparison with IC,U control, \#p<0.05, \#\# $p<0.01$, and \#\#\# $p<0.001$; ${ }^{*}$-comparison between systems, ${ }^{*} p<0.05$ and $\left.{ }^{* *} p<0.01\right)$.

Regarding $\mathrm{M}_{2}$ markers, LPS-treatment induced Vegfa and Il10 expression in the short term, while it inhibited it after 7 days of treatment. Moreover, $T g f b 1$ expression was not affected in the short term but significantly repressed after 7 days of treatment. This long-term effect on $T g f b 1$ expression was significantly reversed by all treatments. On the contrary, the addition of 14Dx-KT NPs produced a significant increase in $I l 10, T g f b 1$, and Vegfa expression with respect to +LPS conditions at both time-points tested. Interestingly, all systems maintained the overexpression of Il10 in time, something that did not occur in simulated inflammatory conditions. Il10 is considered the most important anti-inflammatory cytokine in humans [43], confirming the anti-inflammatory capacity of the systems. These data indicated that KT NPs presented a potent anti-inflammatory behavior improving that of the previously described NAP-based analog. This result was expected as KT is a more potent NSAID than NAP in terms of COX inhibition [21,22]. Finally, regarding the synergistic $I l 12 b$, gene repression was not observed, meaning that the combination of Dx with a stronger COX-inhibitor did not imply a more potent synergistic effect. This result suggested that the COX inhibition was not contributing to the synergistic $I l 12 b$ gene repression in murine macrophages when combining NAP and Dx. Moreover, this synergistic repression was observed for the NAP/Dx system even in non-LPS-activated macrophages 
in which COX was not overexpressed. All these data indicate that the COX-dependent route does not play a key role in the synergistic effect observed, and further studies on the mechanism of action should focus on MAPK pathways and 5-LO metabolism as there are reports of modulation of $I l 12 b$ expression in antigen-presenting cells (i.e., macrophages and dendritic cells, mainly) through these pathways [13-17].

\section{Conclusions}

Anti-inflammatory NPs that combine KT (covalently attached) and Dx (physically entrapped) were successfully prepared, and their biological activity was evaluated. The amount of Dx entrapped by KT-bearing polymer drugs into NPs was optimized by testing different $\% \mathrm{Dx}$ ( $w / w$, with respect to the copolymer) in such a way that the amount of Dx encapsulated was maximized. Moreover, it was demonstrated that the spherical shape, the hydrodynamic properties, and positive surface charge of KT NPs $\left(D_{h}=100-200 \mathrm{~nm}\right.$, PdI below 0.2 , and $\xi$ close to $\left.+30 \mathrm{mV}\right)$ translated into rapid internalization by macrophages through CME and macropinocytosis, two internalization routes that might facilitate the enzymatic and pH-mediated release of KT and Dx in the lysosome. 14Dx-KT NPs and unloaded KT NPs reduced LPS-induced NO release when compared to the control, with the Dx-loaded system more effective at $24 \mathrm{~h}$ due to the early release of the physically entrapped Dx. Moreover, the unloaded KT NPs were able to reduce to almost basal levels (NIC) the expression of all $\mathrm{M}_{1}$ markers tested. The RT-qPCR analysis also concluded that the synergistic inhibition of $I l 12 b$ was not occurring in a significant manner for 14Dx-KT NPs. However, long-term treatment with 14Dx-KT NPs led to Tnfa overexpression and regulation of $I l 12 b$ and $I l 23 a$ expression, reducing it up to normal cellular levels. As a conclusion, the KT-based systems described in this paper present interesting anti-inflammatory activity as they reduced NO released levels and M1 markers expression while increasing M2 markers expression under inflammatory conditions. Moreover, KT-based systems were rapidly internalized by macrophages, which might favor the retention at inflamed areas through the ELVIS effect. Therefore, they could be used by themselves, as well as encapsulating Dx or other hydrophobic drugs, for the treatment of inflammatory processes. Moreover, it was demonstrated that the use of a KT, an NSAID with more potent COX-inhibitory activity did not cause synergistic repression of $I l 12 b$ gene when combined with Dx. This, together with the fact that this synergistic repression was observed for the NAP/Dx system even in non-LPS-activated macrophages in which COX was not overexpressed [11], indicated that the COX-dependent route was not crucial for the synergy observed. Therefore, further studies should be done on NAP/Dx mechanism of action focusing on MAPK pathways and 5-LO metabolism.

Supplementary Materials: The following are available online at http://www.mdpi.com/1999-4923/12/8/723/s1, Figure S1. Color and $\mathrm{pH}$ values of nanoparticles (KT NPs, $3 \mathrm{mg} / \mathrm{mL}$ ) in suspension at different NPs:DMEM volume ratios; Figure S2. Hydrodynamic properties (i.e., diameter (size) in nanometers, polydispersity (PdI) and, zeta potential $(\xi)$ in $\mathrm{mV}$ of nanoparticles (KT NPs, $3 \mathrm{mg} / \mathrm{mL}$ ) in suspension at different NPs:DMEM volume ratios; Figure S3, Surface diagrams representing the variation of the instantaneous molar fraction of HKT in the copolymer; Figure S4, Scanning Electron Microscopy micrograph showing morphology of KT NPs; Figure S5, Mass of dexamethasone encapsulated measured by HPLC for each initial \%Dx $(w / w)$ with respect to poly(HKT-co-VI) copolymer. Results represent mean \pm SD of two independent experiments, $\mathrm{n}=2,{ }^{*} p \leq 0.05$; Figure S6, Quantitative real-time PCR data. Heat map of gene transcript levels of M1 markers in non-LPS activated samples (NIC) treated with free dexamethasone (free Dx, 5.1 $\mu \mathrm{M}$, red), Dx-loaded ketoprofen-bearing NPs (14Dx-KT NPs, 5.1 $\mu \mathrm{M}$ Dx, and $0.045 \mathrm{mg} / \mathrm{mL}$ NPs, white) and unloaded ketoprofen-bearing NPs (KT NPs, $0.045 \mathrm{mg} / \mathrm{mL}$, black) for 1 day (plain) and 7 days (dashed). Results are expressed relative to the corresponding level of expression of each transcript in the untreated sample; Figure S7, Quantitative real-time PCR data. Heat maps of gene transcript levels of (a) M1 markers and (b) M2 markers in inflamed samples (500 ng/mL of LPS) treated with culture media (IC,U, blue), free dexamethasone (free Dx, 5.1 $\mu \mathrm{M}$, red), Dx-loaded ketoprofen-bearing NPs (14Dx-KT NPs, $5.1 \mu \mathrm{M}$ Dx, and $0.045 \mathrm{mg} / \mathrm{mL}$ NPs, white), and unloaded ketoprofen-bearing NPs (KT NPs, $0.045 \mathrm{mg} / \mathrm{mL}$, black) for 1 day (plain) or 7 days (dashed). Results are expressed relative to the corresponding level of expression of each transcript in the non-inflammatory conditions (NIC) untreated sample; Table S1, RT-qPCR primer list; Table S2, Quantitative real-time PCR data. Gene transcript levels of M1 markers under normal cellular conditions (NIC) and of M1 and M2 markers under inflammatory conditions (IC,U), treated with free dexamethasone (free Dx, $5.1 \mu \mathrm{M}$ ), Dx-loaded ketoprofen-bearing NPs (14Dx-KT NPs, $5.1 \mu \mathrm{M}$ Dx, and $0.045 \mathrm{mg} / \mathrm{mL}$ NPs), and unloaded ketoprofen-bearing NPs (KT NPs, $0.045 \mathrm{mg} / \mathrm{mL}$ ) for 1 day or 7 days. Data are presented as mean $\log 2$ variation and standard deviation compared to untreated cells in 2 independent experiments, each quantified in triplicate. 
Author Contributions: Conceptualization, E.E.-C., M.R.A., D.F.B., Y.P., and J.S.R.; methodology, E.E.-C., M.R.A., D.F.B., Y.P., and J.S.R.; investigation, E.E.-C., M.R.A., D.F.B., Y.P., and J.S.R.; data curation, E.E.-C., M.R.A., D.F.B., and Y.P.; writing —original draft preparation, E.E.-C.; writing—review and editing, E.E.-C., M.R.A., D.F.B., Y.P., and J.S.R.; supervision, M.R.A., D.F.B., and J.S.R.; funding acquisition, M.R.A., D.F.B., and J.S.R. All authors have read and agreed to the published version of the manuscript.

Funding: This research was funded by the Spanish Ministry of Science, Innovation and Universities, grant number MAT2017-84277-R and SAF2017-82223-R and by the training program for Academic Staff, grant numbers FPU15/06109 and FPU15/06170, of the Spanish Ministry of Education Culture and Sport.

Acknowledgments: The kind support by Alvaro González-Gómez, Kenny S. Malpartida, Rosana Ramírez, and David Gómez, in the synthesis, cell culture and SEM experiments is greatly appreciated.

Conflicts of Interest: The authors declare no conflict of interest.

\section{References}

1. Dinarello, C.A. Anti-inflammatory agents: Present and future. Cell 2010, 140, 935-950. [CrossRef] [PubMed]

2. Lai, Y.; Dong, C. Therapeutic antibodies that target inflammatory cytokines in autoimmune diseases. Int. Immunol. 2016, 28, 181-188. [CrossRef] [PubMed]

3. Toussirot, E. The IL23/Th17 pathway as a therapeutic target in chronic inflammatory diseases. Inflamm. Allergy Drug Targets 2012, 11, 159-168. [CrossRef] [PubMed]

4. Pfeifle, R. Analysis of the Role of the IL-23/Th17 axis on B Cell-Mediated Autoimmunity. Ph.D. Thesis, Friedrich-Alexander University Erlangen-Nürnberg, Erlangen, Germany, 2017.

5. Ergen, E.N.; Yusuf, N. Inhibition of interleukin-12 and/or interleukin-23 for the treatment of psoriasis: What is the evidence for an effect on malignancy? Exp. Dermatol. 2018, 27, 737-747. [CrossRef] [PubMed]

6. Vom Berg, J.; Prokop, S.; Miller, K.R.; Obst, J.; Kälin, R.E.; Lopategui-Cabezas, I.; Wegner, A.; Mair, F.; Schipke, C.G.; Peters, O.; et al. Inhibition of IL-12/IL-23 signaling reduces Alzheimer's disease-like pathology and cognitive decline. Nat. Med. 2012, 18, 1812-1819. [CrossRef] [PubMed]

7. Mortezavi, M.; Ritchlin, C. IL12/IL23 Inhibition in the treatment of psoriatic arthritis. Curr. Treat. Opt. Rheumatol. 2015, 1, 197-209. [CrossRef]

8. Kotze, P.G.; Ma, C.; Almutairdi, A.; Panaccione, R. Clinical utility of ustekinumab in Crohn's disease. J. Inflamm. Res. 2018, 11, 35-47. [CrossRef]

9. Oppmann, B.; Lesley, R.; Blom, B.; Timans, J.C.; Xu, Y.; Hunte, B.; Vega, F.; Yu, N.; Wang, J.; Singh, K.; et al. Novel p19 protein engages IL-12p40 to form a cytokine, IL-23, with biological activities similar as well as distinct from IL-12. Immunity 2000, 13, 715-725. [CrossRef]

10. Henrickson, S.E.; Ruffner, M.A.; Kwan, M. Unintended immunological consequences of biologic therapy. Curr. Allergy Asthma Rep. 2016, 16, 46. [CrossRef]

11. Espinosa-Cano, E.; Aguilar, M.R.; Vázquez, B.; Román, J.S. Chapter 7-Inflammation-responsive polymers. In Smart Polymers and Their Applications, 2nd ed.; Aguilar, M.R., Román, J.S., Eds.; Woodhead Publishing: Cambridge, UK, 2019; pp. 219-254.

12. Paik, J.H.; Ju, J.H.; Lee, J.Y.; Boudreau, M.D.; Hwang, D.H. Two opposing effects of non-steroidal anti-inflammatory drugs on the expression of the inducible cyclooxygenase. Mediation through different signaling pathways. J. Biol. Chem. 2000, 275, 28173-28179. [CrossRef]

13. Alaseem, A.M.; Madiraju, P.; Aldebeyan, S.A.; Noorwali, H.; Antoniou, J.; Mwale, F. Naproxen induces type $\mathrm{X}$ collagen expression in human bone-marrow-derived mesenchymal stem cells through the upregulation of 5-lipoxygenase. Tissue. Eng. Part A 2015, 21, 234-245. [CrossRef] [PubMed]

14. Whittaker, D.S.; Bahjat, K.S.; Moldawer, L.L.; Clare-Salzler, M.J. Autoregulation of human monocyte-derived dendritic cell maturation and IL-12 production by cyclooxygenase-2-mediated prostanoid production. J. Immunol. 2000, 165, 4298-4304. [CrossRef] [PubMed]

15. Mitsuhashi, M.; Liu, J.; Cao, S.; Shi, X.; Ma, X. Regulation of interleukin-12 gene expression and its anti-tumor activities by prostaglandin E2 derived from mammary carcinomas. J. Leukoc. Biol. 2004, 76, 322-332. [CrossRef] [PubMed]

16. Bedognetti, D.; Roelands, J.; Decock, J.; Wang, E.; Hendrickx, W. The MAPK hypothesis: Immune-regulatory effects of MAPK-pathway genetic dysregulations and implications for breast cancer immunotherapy. Emerg. Top. Life Sci. 2017, 1, 429-445. 
17. Boucher, J.G.; Parato, K.A.; Frappier, F.; Fairman, P.; Busca, A.; Saxena, M.; Blahoianu, M.A.; Ma, W.; Gajanayaka, N.; Parks, R.J.; et al. Disparate regulation of LPS-induced MAPK signaling and IL-12p40 expression between different myeloid cell types with and without HIV infection. Viral Immunol. 2010, 23, 17-28. [CrossRef]

18. Burnett, B.P.; Levy, R.M. 5-Lipoxygenase metabolic contributions to NSAID-induced organ toxicity. Adv. Ther. 2012, 29, 79-98. [CrossRef]

19. Brenner, R.; Ayala, S.; Garda, H. Effect of dexamethasone on the fatty acid composition of total liver microsomal lipids and phosphatidylcholine molecular species. Lipids 2002, 36, 1337-1345. [CrossRef]

20. Ma, W.; Gee, K.; Lim, W.; Chambers, K.; Angel, J.B.; Kozlowski, M.; Kumar, A. Dexamethasone inhibits IL-12p40 production in lipopolysaccharide-stimulated human monocytic cells by down-regulating the activity of c-Jun N-Terminal Kinase, the activation Protein-1, and NF- $\mathrm{kB}$ transcription factors. J. Immunol. 2004, 172, 318-330. [CrossRef]

21. Botting, R.M. Inhibitors of cyclooxygenases: Mechanisms, selectivity and uses. J. Physiol. Pharmacol. 2006, 57, 113-124.

22. Rao, P.; Knaus, E.E. Evolution of nonsteroidal anti-inflammatory drugs (NSAIDs): Cyclooxygenase (COX) inhibition and beyond. J. Pharm. Pharm. Sci. 2008, 11, 81-110. [CrossRef]

23. Bareford, L.M.; Swaan, P.W. Endocytic mechanisms for targeted drug delivery. Adv. Drug Deliv. Rev. 2007, 59, 748-758. [CrossRef] [PubMed]

24. Al-Khoury, H.; Espinosa-Cano, E.; Aguilar, M.R.; Roman, J.S.; Syrowatka, F.; Schmidt, G.; Groth, T. Anti-inflammatory surface coatings based on polyelectrolyte multilayers of heparin and polycationic nanoparticles of naproxen-bearing polymeric drugs. Biomacromolecules 2019, 20, 4015-4025. [CrossRef] [PubMed]

25. Suarez, P.; Rojo, L.; González-Gómez, Á.; Román, J.S. Self-Assembling gradient copolymers of vinylimidazol and (Acrylic)ibuprofen with anti-inflammatory and zinc chelating properties. Macromol. Biosci. 2013, 13, 1174-1184. [CrossRef]

26. Srivastava, A.; Waite, J.H.; Stucky, G.D.; Mikhailovsky, A. Fluorescence investigations into complex coacervation between polyvinylimidazole and sodium alginate. Macromolecules 2009, 42, 2168-2176. [CrossRef] [PubMed]

27. Livak, K.J.; Schmittgen, T.D. Analysis of relative gene expression data using real-time quantitative PCR and the 2(-Delta Delta C(T)) Method. Methods 2001, 25, 402-408. [CrossRef]

28. DiCiccio, J.E.; Steinberg, B.E. Lysosomal $\mathrm{pH}$ and analysis of the counter ion pathways that support acidification. J. Gen. Physiol. 2011, 137, 385-390. [CrossRef]

29. d'Arcy, R.; Tirelli, N. Fishing for fire: Strategies for biological targeting and criteria for material design in anti-inflammatory therapies. Polym. Adv. Technol. 2014, 25, 478-498. [CrossRef]

30. Bhattacharjee, S. DLS and zeta potential-What they are and what they are not? J. Control. Release 2016, 235, 337-351. [CrossRef]

31. Cheng, C.J.; Tietjen, G.T.; Saucier-Sawyer, J.K.; Saltzman, W.M. A holistic approach to targeting disease with polymeric nanoparticles. Nat. Rev. Drug Discov. 2015, 14, 239-247. [CrossRef]

32. Sadat, S.M.A.; Jahan, T.; Haddadi, A. effects of size and surface charge of polymeric nanoparticles on "in vitro" and "in vivo" applications. J. Biomater. Nanobiotechnol. 2016, 7, 91-108. [CrossRef]

33. Pillay, V.; Murugan, K.; Choonara, Y.E.; Kumar, P.; Bijukumar, D.; Du Toit, L.C. Parameters and characteristics governing cellular internalization and trans-barrier trafficking of nanostructures. Int. J. Nanomed. 2015, 10, 2191-2206. [CrossRef] [PubMed]

34. Banik, B.L.; Fattahi, P.; Brown, J.L. Polymeric nanoparticles: The future of nanomedicine. Wiley Interdiscip. Rev. Nanomed. Nanobiotechnol. 2016, 8, 271-299. [CrossRef] [PubMed]

35. Kou, L.; Sun, J.; Zhai, Y.; He, Z. The endocytosis and intracellular fate of nanomedicines: Implication for rational design. Asian J. Pharm. Sci. 2013, 8, 1-10. [CrossRef]

36. Vangara, K.K.; Liu, J.L.; Palakurthi, S. Hyaluronic acid-decorated PLGA-PEG nanoparticles for targeted delivery of SN-38 to ovarian cancer. Anticancer. Res. 2013, 33, 2425-2434.

37. Yameen, B.; Choi, W.I.; Vilos, C.; Swami, A.; Shi, J.; Farokhzad, O.C. Insight into nanoparticle cellular uptake and intracellular targeting. J. Control. Release 2014, 190, 485-499. [CrossRef] 
38. Sahin, M.; Arslan, C.; Nazıroğlu, M.; Tunç, E.; Demirci, M.; Sutcu, R.; Yilmaz, N. Asymmetric dimethylarginine and nitric oxide levels as signs of endothelial dysfunction in behcet's disease. Ann. Clin. Lab. Sci. 2006, 36, 449-454.

39. Reichel, D.; Tripathi, M.; Perez, J.M. Biological effects of nanoparticles on macrophage polarization in the tumor microenvironment. Nanotheranostics 2019, 3, 66-88. [CrossRef]

40. Mulén, B.; Rojas, J.M.; Pérez-Yagüe, S.; Morales, M.P.; Barber, D.F. Polyethylenimine-coated SPIONs trigger macrophage activation through TLR-4 signaling and ROS production and modulate podosome dynamics. Biomaterials 2015, 52, 494-506.

41. Ghezzi, P.; Sacco, S.; Agnello, D.; Marullo, A.; Caselli, G.F.; Bertini, R. Lps induces IL-6 in the brain and in serum largely through TNF production. Cytokine 2000, 12, 1205-1210. [CrossRef]

42. Zakharova, M.; Ziegler, H.K. Paradoxical Anti-Inflammatory actions of TNF- $\alpha$ : Inhibition of IL-12 and IL-23 via TNF receptor 1 in macrophages and dendritic cells. J. Immunol. 2005, 175, 5024-5033. [CrossRef]

43. Shachar, I.; Karin, N. The dual roles of inflammatory cytokines and chemokines in the regulation of autoimmune diseases and their clinical implications. J. Leukoc. Biol. 2013, 93, 51-61. [CrossRef] [PubMed]

(C) 2020 by the authors. Licensee MDPI, Basel, Switzerland. This article is an open access article distributed under the terms and conditions of the Creative Commons Attribution (CC BY) license (http://creativecommons.org/licenses/by/4.0/). 